\title{
La iniciativa europea para la democracia y su impacto en la Comunidad Andina. Caso Colombia
}

\begin{abstract}
Ana Toro*
Las perspectivas sobre la democracia y las relaciones internacionales, que tanto Estados Unidos como la Unión Europea desarrollaron, a partir de la Segunda Guerra Mundial cuando los regímenes fascistas se habían apoderado de los países de Europa Occidental y amenazaban con expandirse por todo el continente, no pueden ser comparadas fácilmente. Los contextos históricos de las dos regiones fueron distintos y, si bien guardaron similitudes en cuanto a retórica y valores, en la práctica se trató de procesos diferentes. El orden mundial estaba en decadencia y los Estados Unidos se preparaban para convertirse en la primera potencia económica y bélica a nivel mundial, con capacidad para influir de manera determinante en el nuevo orden internacional. En esa medida estaba a punto de experimentar un cambio drástico en cuanto a sus principios republicanos fundacionales y acentuar, ya como potencia, sus tendencias intervencionistas en todo el mundo.

En sus declaraciones fundacionales, la Unión Europea ha declarado estar adscrita a los principios de Libertad, Democracia, respeto a los Derechos Humanos, libertades fundamentales y Estado de Derecho. El Parlamento Europeo se ha manifestado como un firme defensor de estos principios que vienen de la tradición democrática europea occidental. Con estos antecedentes, en 1994 surge la "Iniciativa Europea Para la Democracia y los Derechos Humanos (IEDDH)", cuyo objetivo principal es fomentar los Derechos Humanos, la Democracia y la prevención de los conflictos en terceros países. Para cumplir con este cometido han sido implementados algunos mecanismos financieros y otros que incluyen la participación de la sociedad civil organizada cuyo papel ha sido reconocido, tanto en el ámbito nacional como internacional. ${ }^{1}$

El conflicto colombiano es el más grave en América Latina y ha producido una de las peores crisis humanitarias de todo el mundo ya que tiene el más elevado número de desplazados internos y amenaza la seguridad regional. Al
\end{abstract}

\footnotetext{
* Socióloga, graduada en la Pontificia Universidad Católica del Ecuador, PUCE. Trabaja en gestión pública en proyectos socioculturales. anamaria.torogalarraga@gmail.com

1 Antecedentes presentados en Iniciativa Europea para la Promoción de la Democracia y Derechos Humanos. Programa de Presentación de Proyectos en Derechos Humanos y Democracia. Perú, 2006. http://www.guiafc.com/documentos/2007-EuropeAid-124355.pdf, visitado el 20 de junio de 2008.
} 
convertirse en un factor de inestabilidad política que afecta al conjunto del área andina está directamente relacionado con el narcotráfico, la emigración y el refugio. A la hora de evaluar las políticas europeas es fundamental tener en cuenta la complejidad institucional de la Unión Europea porque los distintos órganos y Estados que la componen tienen opiniones divergentes respecto a la problemática colombiana y a la forma de actuar; todavía hay quienes son más proclives a políticas de fuerza y menos a las cuestiones de derechos humanos por lo que los instrumentos europeos de Promoción de la Democracia no alcanzaron las expectativas creadas en Colombia y en la Región Andina.

\section{Antecedentes}

\subsection{La consolidación de diversas perspectivas democráticas a fines del siglo $X X$}

El mundo político internacional se caracteriza en la actualidad por la expansión de los sistemas democráticos, al menos a nivel discursivo. ${ }^{2}$ El proceso se profundizó con el repentino e inesperado final de la Guerra Fría y la desintegración del bloque soviético en los años posteriores a 1989. Estados Unidos y Europa, a través de diversas formas -entre ellas la ayuda financiera y la inversión extranjera directa- influyeron para que se instalaran regímenes al estilo de la democracia occidental en la mayor parte de los antiguos países comunistas y del tercer mundo. Este cambio ideológico y político no ha dejado de tener un trasfondo de seguridad y ha significado en buena medida un replanteamiento de las doctrinas y procedimientos propios del conflicto este - oeste que tuvieron al mundo bajo la incertidumbre de un posible enfrentamiento bélico de escala mundial, con difíciles pronósticos dado el excesivo arsenal nuclear de las dos potencias hegemónicas.

La caída del muro de Berlín cambió la estructura del sistema internacional de una estructura bipolar a una unipolar que también acentuó la supremacía estadounidense, básicamente en términos militares. Sin embargo, los países de

2 Existen regímenes que se asumen como democráticos pero no cumplen las condiciones necesarias, estas serán explicadas a profundidad en el primer capítulo de esta investigación. 
Europa Occidental, que después de la Segunda Guerra Mundial habían recibido en las últimas décadas del siglo XX la ayuda de los Estados Unidos a través del Plan Marshal, habían avanzado significativamente en el campo de las doctrinas y planteamientos de la negociación de conflictos y mecanismos de construcción de la Paz dentro de una perspectiva multilateralista de las relaciones internacionales. ${ }^{3}$ Desde 1985 estas tendencias recibieron el aporte académico de institutos especializados, entre ellos, la Escuela de Copenhague ${ }^{4}$, los cuales contribuyeron a fortalecer una concepción de democracia europea basada en los principios de la cooperación internacional y los Derechos Humanos. Por otro lado, los países satélites de la ex Unión Soviética pasaron a formar parte de la Comunidad Económica Europea luego de la reunificación alemana. En 1992 se firmó el Tratado de Maastricht que cambió los tradicionales acuerdos en materia económica y de seguridad, para incorporar un componente político absolutamente novedoso dentro de los sistemas de integración adoptando, por esta razón, el nombre de Unión Europea.

También en los Estados Unidos, aunque con matices triunfalistas y en el marco del ascenso del neoliberalismo económico, se generaron tendencias hacia la reconfiguración de los parámetros democráticos tras el fin de la Guerra Fría. Aparecieron publicaciones como "El Fin de la Historia" de Francis Fukuyama; "La Tercera Ola de Democratización" de Samuel Huntington, en las que se acentúa esta perspectiva. En el plano de las teorías de las relaciones internacionales se dio un giro desde el realismo tradicional y el liberalismo norteamericano hacia nuevos planteamientos como el Neorrealismo, la Interdependencia Compleja ${ }^{5}$, entre otros. Estas ideas tuvieron una fuerte influencia durante la administración del presidente Clinton (20 de enero de 1993 a 20 de enero de 2001), con sensibles acercamientos, en el primer momento con el correspondiente discurso político ensayado por entonces por la Unión Europea. A nuestro

3 Se refiere al Programa de Recuperación Europea (ERP en Inglés) que consiste en un aporte económico a los países de menor desarrollo relativo, con el fin de reducir las oportunidades políticas del comunismo. La medida se fue implementada dentro del llamado Plan Marshall en junio de 1947.

4 "Escuela de Copenhague" fue un término acuñado en 1997 para referirse a las investigaciones realizadas por el Instituto de Investigación para la Paz de Copenhague, que ha sido pionero en el tema de "Seguridad Europea", basada en el marco conceptual del constructivismo, tendencia crítica del realismo y neorrealismo dominantes durante el siglo XX.

5 Esta teoría surgió en los años 70 y posteriormente dio lugar al Neoliberalismo Institucional que ha sido el lineamiento adoptado por la Unión Europea durante su vida institucional. 
juicio, las diferencias en las concepciones respectivas sobre la democracia se definirían más tarde.

Tras la caída del Muro de Berlín, la mayor aspiración europea ha sido alcanzar influencia política internacional y un liderazgo intelectual en el mundo a partir de su habilidad negociadora entre la potencia hegemónica y terceros países incluidos el área de la ex Unión Soviética. El fuerte europeo ha sido la Cooperación Internacional bajo el signo del desarrollo, la promoción de la democracia y los derechos humanos, por lo que muy bien se podría hablar de un "paradigma europeo" afianzado en los principios de la Revolución Francesa. ${ }^{6}$

Por lo expuesto, no sería posible asumir una concepción unívoca de democracia al hablar de los sistemas promovidos por los Estados Unidos y los países europeos como estados modernos. Las diferencias no son recientes sino que parten de los mismos procesos de formación y desarrollo de sus concepciones políticas. A inicios del siglo XX ya se marcaron diferencias cruciales que orientaron al mundo hacia dos concepciones distintas que pronto entraron en conflicto: la democracia liberal y la democracia socialista dentro de cuyos bloques también se establecieron diferencias notables.

Los Estados Unidos han abanderado el discurso de la Democracia Liberal; los padres fundadores delinearon un Estado Liberal con una sociedad civil promovida por la libre competencia económica, aunque regulada por normas federales, dentro de un proyecto Constitucional centrado en la limitación de los poderes públicos -Poder Legislativo, Poder Ejecutivo y Poder Judicial-. Cada uno ejerciendo restricciones sobre los demás, para limitar el poder de las mayorías al interior del Legislativo. ${ }^{7}$ Pero hacia fines del siglo XIX, empezaron a demostrar su ímpetu expansionista e intervencionista, basado en los principios

6 El racionalismo de Descartes terminó con la idea del Derecho Divino atribuido a los monarcas europeos desde el siglo XVIII y dio paso al pensamiento de la Ilustración, cuyos principios se basaban en la razón, la igualdad y la libertad que sirvió de impulso a la independencia de las trece colonias norteamericanas y fue el fundamento ideológico para la Revolución Francesa que instauró a la República.

7 José Francisco García García, Tres aportes fundamentales de El federalista a la teoría constitucional moderna, Revista de Derecho, Vol. XX Num. 1. Julio de 2007. Según la filosofía de El federalista; las mayorías pueden causar el mayor daño a la república representativa por acaparar el poder sin considerar a las minorías y por consiguiente a la voluntad ciudadana. 
de la "Doctrina del Destino Manifiesto" y la "Doctrina Monroe" (1823) que se promocionó con el eslogan "América para los americanos" y se dispuso a impedir que alguna potencia extranjera -entiéndase europea- intervenga política, económica o militarmente en su área de influencia.

Mientras tanto, América Latina ha sido históricamente un subcontinente determinado por grandes desigualdades sociales y económicas y con experiencias de desarrollo diferenciadas que responden, en parte, a la presencia o influencia permanente de potencias extranjeras en los Estados (España y Portugal primero, y desde el siglo XIX los Estados Unidos) lo cual ha sido unos de los factores que ha impedido la formación de una sociedad civil fuerte y exigente de sus derechos políticos. En algunos países, especialmente Argentina y Brasil, la inmigración europea extensiva desde comienzos del siglo XX aceleró el desarrollo industrial ya que se aumentó el aporte de inversión extranjera directa y mano de obra.

Por su parte, si bien Colombia, desarrolló una temprana industrialización y "hasta fines de los ochenta, era el país más estable relativamente y de mayor crecimiento de la región a pesar de mantener una conflictiva situación política interna, en los años noventa ha demostrado tendencias hacia una enorme complejidad. Esta es una situación que combina crecimiento económico con enfrentamiento político e ideológico; disposición de grandes recursos especialmente petroleros, industriales y de inversión extranjera con niveles de conflictividad política y delincuencia organizada, especialmente con la incidencia del narcotráfico involucrado en todos los niveles. A pesar de ello y de la estrechez de su sistema político (con una cierta apertura desde 1991 con la nueva Constitución colombiana) Colombia presenta una situación de crisis que es necesario estudiar con más profundidad, especialmente porque se ha convertido en un gene-

8 La expresión fue utilizada por primera vez por John Cotton en 1630 para referirse a las trece colonias como las llamadas a expandir su territorio: "Ninguna nación tiene el derecho de expulsar a otra, si no es por un designio especial del cielo como el que tuvieron los israelitas, a menos que los nativos obraran injustamente con ella. En este caso tendrán derecho a entablar, legalmente, una guerra con ellos así como a someterlos". En 1845, la frase fue utilizada por un periodista John L. O' Sullivan quien se basa también en los principios divinos atribuidos a Estados Unidos para extenderse en el continente y, por último, los republicanos la emplearon en 1890 para justificar la expansión de Estados Unidos por América del norte. 
rador de inestabilidad, con impactos de todo género en su entorno subregional inmediato -los países del área andina-e incluso sobre la región sudamericana. ${ }^{9}$

Además de la inestabilidad política, han sido también características de la región la pobreza y el subdesarrollo económico y social, especialmente en sectores rurales y urbano-marginales que han merecido el nombre de "cinturones de pobreza". En su momento, gobiernos con tendencias nacionalistas y organismos regionales -como la $\mathrm{CEPAL}^{10}$ - pretendieron eliminarlos mediante un proceso de industrialización por sustitución de importaciones en las décadas de los 70, aunque con escaso éxito. La cooperación internacional también se hizo presente para tratar de superar las reincidentes crisis económicas, ocasionadas por la caída de precios de los productos agrícolas de exportación. Entre los años 1961 y 1970, con la iniciativa norteamericana de Alianza para el Progreso, se implementaron programas específicos que buscaban fomentar el desarrollo y contener el avance comunista. ${ }^{11}$

En la década de los ochentas, América Latina experimentó un proceso de democratización formal, consistente en el traspaso del poder militar a los nuevos gobiernos civiles que iniciaron sus mandatos en medio de una severa crisis de la deuda externa la cual, de acuerdo a las sugerencias y condiciones del Fondo Monetario Internacional, debía ser combatida con ajustes de corte neoliberal. Tales ajustes se hacían en el contexto de los procesos de reordenamiento del mundo a las necesidades del mercado mundial en el ascenso de la economía neoliberal. Los impactos significaron más bien el aumento de la pobreza, el desempleo y el subempleo que han llevado a una mayor desigualdad social no solo en la región sino a nivel mundial; en consecuencia significaron también un incremento en los niveles de violencia y de actividades ilícitas.

Dentro de este contexto, ha sido de interés académico y político, investigar las razones que llevan paulatinamente a un mayor acercamiento de Europa hacia América Latina, sobretodo en la Región Andina pues es una zona de

9 Eduardo Lora, Perspectivas del desarrollo económicas colombiano: Los retos del gobierno de Álvaro Uribe Vélez, Kellog Institute, Colombia, 2003. Tomado del Sitio Web:

http://www.ideaspaz.org/eventos/download/eduardo_lora.pdf. Visitado el 18 de junio de 2009.

10 Comisión Económica para América Latina y el Caribe, creada por el Consejo Económico y Social de las Naciones Unidas (ECOSOC), el 25 de febrero de 1948, por resolución 106.

11 Centro de Estudios y Documentación Sociales, Las relaciones internacionales, Volumen 3 de Manuales de educación cívica Número 3 de Colección imagen de los Estados Unido, Editorial Jurídica de Chile, Chile, 1963. 
enorme complejidad política. Para ello se analizó la Iniciativa Europea para la Democracia y los Derechos Humanos como una forma de expandirse no solo en términos de apertura de mercados sino también en términos del segundo pilar proclamado por la Unión Europea, es decir, de la política exterior y de seguridad que está regulada en el título V del Tratado de la Unión Europea, basada en la democracia y la promoción de los derechos humanos.

Los discursos que plantea la Unión Europea se basan en los principios democráticos heredados históricamente ${ }^{12} \mathrm{y}$ aparecen como un aporte gratuito de Europa para el mundo. No obstante, fue necesario tomar en cuenta uno de los legados más importantes de la teoría realista - adoptado por neoliberales e interdependentistas - el cual afirma que todos los estados o confederaciones de estados tienen en último término una razón de Estado, la cual responde a intereses históricos específicos. Por este motivo una de las incógnitas que surgió al momento de plantearse el problema de investigación fue: qué mueve a la Unión Europea a insertarse en espacios geopolíticos tradicionalmente dominados por los Estados Unidos considerando, que en base a este principio - del interés del Estado - puede ser descartada la posibilidad de que la cooperación sea un instrumento con finalidades filantrópicas o altruistas puesto que éstas responderían a un conjunto de ideas basadas en imágenes ideales que no consideran cálculos y capacidades completas de influencia exterior.

¿Cuáles son las razones subyacentes de la prioridad que la Unión Europea ha dado a Colombia dentro de la "Iniciativa Europea para la Democracia y los Derechos Humanos" cuyo objetivo es la promoción de una política de paz? y ¿Cuáles han sido los impactos y resultados de los mecanismos empleados para el efecto? Se trata descubrir cuál es la lógica de funcionamiento de la Política de Promoción de la Democracia y los Derechos Humanos adoptado por la Unión Europea e insertado en América Latina; principalmente en Colombia como país prioritario puesto que por su cercanía geográfica, la afinidad histórica y la pertenencia a la Comunidad Andina de Naciones hace que los resultados positivos o negativos incidan directamente en el Ecuador. La particularidad colombiana es que tiene ingresos per cápita superiores a la media y recibe mayor cantidad de ayuda junto con México y Guatemala que son parte de los 31 países prioritarios de esta iniciativa.

12 De la Revolución Inglesa, Revolución Francesa, Escuela de Copenhague. 
Se podría conocer este tema desde varias perspectivas teóricas como la Teoría de Cooperación Internacional, Ayuda Oficial al Desarrollo, Geopolítica, Realismo y Neorrealismo. No obstante, la Teoría del Neoliberalismo Institucional fue analizada y tomada como el mejor acercamiento para la resolución del problema puesto que la teoría basada en intereses explica la manera en que los estados se unen, enfocándose en las ganancias absolutas -y no relativas como en el caso de los realistas- a fin de conseguir beneficios mutuos. Y por otro lado, fue necesario analizar el interés de la Unión Europea para promover el Estado de Derecho y las Instituciones Democráticas por lo que se empleó el marco conceptual de Poliarquía expuesto por Robert Dahl que brinda los insumos necesarios para entender el sistema democrático que exporta Europa a través de la "Iniciativa para la Democracia y Derechos Humanos".

\subsection{Democracia e Internacionalismo: ¿Son partes de un mismo pro- ceso global?}

La retórica europea sustenta sus múltiples iniciativas hacia la cooperación internacional en la necesidad de construir un ambiente de paz internacional. Por este motivo, uno de los ejes principales es la preocupación por la consolidación de la democracia en los países del llamado tercer mundo. Es necesario realizar una revisión teórica para entender qué está detrás de estos acuerdos de asociación y de cooperación que un gran impulso por parte de los países miembros de la Comunidad pero han encontrado serias trabas por parte de la contraparte andina.

Europa mantiene una línea tradicionalista en su concepción de democracia y resulta necesario entender su perspectiva y los principios que impulsan a través de la cooperación internacional. En las últimas décadas, Europa se ha definido a sí misma como "social demócrata"13, sustentando la asociación entre el crecimiento económico con la justicia social, sin por ello abandonar el sistema económico capitalista. Más bien ha pretendido reformarlo, a partir de leyes y políticas que respondan a la satisfacción de las necesidades de todos, basándose en los principios de igualdad, fraternidad y libertad. Tampoco rechaza absolutamente al liberalismo, sino que considera algunos de sus planteamientos filosó-

13 Como parte de un proceso único heredado de la Revolución Inglesa, Revolución Francesa, Escuela de Copenhague, Guerras Mundiales, Guerra Fría, entre otras. 
ficos, como el derecho al sufragio, como indispensable para logar los derechos de los ciudadanos.

\title{
1.3. Procesos recientes de democratización
}

Samuel Huntington, en la Tercera Ola de la Democratización, analiza el proceso de democratización en el mundo y afirma que este se ha realizado en tres etapas a las cuales llama "Olas" y "Contra olas". "El término ola de democratización es un conjunto de transiciones de un régimen no democrático a otro democrático, que ocurren en determinado periodo de tiempo y que superan significativamente a las transiciones en dirección opuesta, durante ese mismo periodo" ${ }^{14}$ este proceso ocurre mediante la elección de autoridades gubernamentales por elecciones libres y competitivas.

\begin{abstract}
Al final de la década de los 80 , la ola democrática empezó a penetrar al mundo comunista. Primero fue Hungría (1988) y luego el régimen comunista de Alemania Oriental (1989). Lo más importante de esta etapa es que fue un momento universal. En el transcurso de 15 años la ola democratizadora se trasladó a lo largo de la Europa del Sur, salió de Latinoamérica, se trasladó a Asia y en 1974 acabó con las dictaduras del bloque soviético. Para 1990, de los 10 países sudamericanos que no tenían gobiernos democráticos, los 9 ya los tenían. Según Freedom House, en esa época el 32\% de la población mundial vivía en países libres. En 1990, cerca del 39\% vivía en sociedades libres. Entre 1973 y 1990, la cantidad absoluta de estados autoritarios disminuyó por primera vez."15.
\end{abstract}

En esta última ola surgieron nuevas tendencias sobre la democracia, enmarcadas en la coyuntura del fin de la Guerra Fría.

14 Curiosidades de la Ciencia, Samuel Huntington. Tomado del Sitio Web: http://www. curiosidadesdelaciencia.com/ciencias-sociales/ciencia-politica/84-olas-de-democratizacionsamuel-huntington, visitado el 14 de julio de 2009.

15 Samuel Huntington, Síntesis de la Tercera Ola, Paidós, 1994.Tomado del Sitio Web: http://www. fcs.edu.uy/enz/licenciaturas/cicloinicial/problemasdesarrollo/Sintesis $\% 20 \mathrm{~S} . \% 20$ Huntington $\% 20$ La\%20tercera\%20ola.pdf. Visitado el 28 de septiembre de 2009. 
Es así como los aportes de la Escuela de Copenhague, por un lado, y de Francis Fukuyama con su libro "El Fin de la Historia", por otro, entre otras cosas, contribuyeron a un nuevo orden internacional en el cual la democracia es considerada como un ideal a alcanzar por las sociedades. Es decir, la democracia como sistema de gobierno se considera - de acuerdo con estas teorías- una suerte de meta que todos los estados deben alcanzar, o como se dirá más adelante, the only game in town. Esta nueva definición surge con fuerza desde los años 90, después del fin de la Guerra Fría, particularmente en aquellos países que por más de cuatro décadas estuvieron bajo la tutela de la Unión Soviética o que permanecieron relegados durante de la Guerra Fría. Las nuevas visiones sirvieron para promover la democracia como modelo en los países del tercer mundo. Sin embargo, como veremos luego, estas visiones mantenían variantes entre una tendencia paternalista o intervencionista (por parte de los Estados Unidos) y una línea más multilateralista sostenido por la tendencia neoliberalista institucional.

\section{La promoción de la democracia, arista de la cooperación internacional}

La cooperación internacional tiene varios ámbitos de aplicación como la erradicación de la pobreza, la lucha contra las drogas, la eliminación del terrorismo, la ayuda humanitaria, la promoción de la democracia, entre otros. Este último surgió como instrumento de cooperación internacional en la década de los 90, no obstante, se lo practicaba desde los siglos 18 y 19 con políticas norteamericanas como el Destino Manifiesto y la Doctrina Monroe. Ambas han hecho que se vincule a la Promoción de la Democracia como una iniciativa de Estados Unidos, que buscaría difundir la democracia en todo el hemisferio como el régimen de gobierno más deseable para todas las naciones. ${ }^{16}$ Después de la Guerra Fría, esta idea pasó a formar parte de la Agenda Internacional de

16 Cabe señalar que bajo la concepción del Destino Manifiesto y la Doctrina Monroe, la promoción de la democracia no estaría encaminada a preservar la paz en el mundo sino que buscaría la consolidación del interés nacional estadounidense que para ese entonces estaba relacionado con la expansión territorial y con evitar a toda costa la influencia de potencias extranjeras en el continente americano; la idea democrática empezaba a ser utilizada como justificativo del accionar internacional de Estados Unidos. 
Ayuda Oficial al Desarrollo instaurada por las Naciones Unidas y otros Organismos Internacionales, Organizaciones No Gubernamentales y Estados, entre ellos, los miembros de la Unión Europea.

El interés nacional es un "concepto utilizado como instrumento de acción política desde el siglo XVI, y en nuestro siglo como instrumento analítico, si bien resultó menos preciso que el clásico concepto de "razón de Estado", por la polémica entre objetivistas, tales como Morgenthau, que lo definen en términos de incremento de poder, y subjetivistas, como Snyder, que consideran que el interés nacional está determinado por las preferencias subjetivas de los líderes políticos. El interés nacional puede definirse en dos niveles: -a nivel de las aspiraciones, brota de la historia y de la ideología, como proyección de la imagen de un querer ser, expresión de un voluntarismo político frecuentemente carente de fundamento real en las capacidades y recursos disponibles por el Estado; -a nivel de actividades operativas, proviene de consideraciones prácticas y circunstanciales, se basa en una apreciación más o menos correcta de las capacidades y recursos disponibles. De la adecuada tensión entre ambos niveles (el querer-ser futuro y el poder-ser de un momento determinado) emana el dinamismo político del Estado. No existe dinamismo cuando la aspiración futura supera de tal modo a las posibilidades que es irrealizable, y cuando es tan limitada y temerosa que queda incluso por debajo de las posibilidades reales. ${ }^{17}$

Los intereses del Estado se representan en construcciones políticas complejas y más aún, cuando se trata de una comunidad de naciones como la Unión Europea que tiene un origen sui generis, carácter supranacional y mantiene una permanente competencia con Estados Unidos para alcanzar protagonismo político en el escenario internacional, aunque sus capacidades reales en términos económicos, militares y de poder son inferiores a las norteamericanas por lo que han construido un discurso basado en el multilateralismo antes que en el militarismo. Esta situación evoca a la disputa dentro de las teorías de las relaciones internacionales que se da entre el realismo y el liberalismo - idealismo aunque posteriormente se produjo un debate entre el neorrealismo y el neoliberalismo que trajeron consigo el Neoliberalismo Institucional que nos

17 Eumed.net, Glosario de Términos Políticos Usuales. Tomado del Sitio Web: http://www.eumed. net/dices/definicion.php?dic=3\&def=361, visitado el 4 de Agosto de 2009 
brinda un acercamiento a las tendencias actuales de la Unión, como se explica a continuación.

Con estos antecedentes, los enfoques teóricos que han permitido resolver las interrogantes son dos: El Neoliberal Institucionalismo cuyos representantes son Robert Keohane y Joseph $\mathrm{Nye}^{18}$ que brinda un mayor énfasis a la capacidad de cooperación interestatal debido a la confluencia de intereses comunes entre los países, lo cuales, ayudados por instituciones internacionales pueden trabajar conjuntamente para conseguir beneficios públicos. Y la Teoría de la Democracia, expuesta por Robert Dahl ${ }^{19}$ y dos de sus discípulos que han tomado como base el concepto de poliarquía: Guillermo O’Donnell que adapta ese concepto a América Latina y Seymour Martín Lipset que se centra en el proceso de democratización de los países en desarrollo.

Europa mantiene el anhelo de recuperar su protagonismo a escala mundial pero su objetivo no es en términos de poder tales como los que se definen en la teoría realista sino que se enfoca principalmente en una política de prestigio que le permita exportar su riqueza ideológica para alcanzar una posición relevante dentro de un sistema multipolar que se abre. Además, fundamenta el multilateralismo como el principal instrumento para la resolución de conflictos, a la vez que se vuelve un referente en términos de cooperación internacional basado en una serie de valores democráticos que tienen el reconocimiento de ser el único ente que ha logrado la confluencia de países que décadas anteriores habían estado enfrentados en un conflicto mundial y se concreta en la elección de Colombia como un país prioritario ya que éste es el "prototipo de problema que puede resolverse por una vía alternativa al uso de la fuerza".

Europa ha sido el escenario de dos conflictos mundiales y estuvo en medio de la Guerra Fría, durante ese tiempo se buscó enmendar los daños económicos, sociales y políticos de aquellos conflictos bajo la premisa de que no se vuelvan a repetir y por ello, se construyó un discurso multilateralista y en contra del armamentismo norteamericano aunque las razones para no rearmarse no eran puramente ideológicas sino también económicas pues el esplendor del imperio

18 Se han tomado los principios expuestos en el capítulo "Cooperación y Discordia en la Política Económica Mundial”, del texto de Robert Keohane y Joseph Nye, "Cooperación y Discordia en la Politica Económica Mundial”, Grupo Editor Latinoamericano, Argentina, 1988.

19 Se parte de la definición de Poliarquía que es expresada por Robert Dahl en 1971 y cuyos seguidores - Guillermo O’Donnel y Seymour Lipset - desarrollaron en las décadas posteriores. 
Francés, Germano e Inglés no se pudo recuperar en los siglos XX y XXI tanto por la hegemonía norteamericana como por el surgimiento de nuevos mercados como Japón y los tigres asiáticos.

\section{Política europea de promoción de la Democracia y Derechos Humanos}

Las declaraciones de la Unión Europea encajan en el marco conceptual de la Poliarquía, expuesto por Robert Dahl, pues incorpora tres condiciones básicas para la consolidación de la democracia: la existencia de un Estado reconocido por la comunidad internacional, la celebración periódica de elecciones libres y la existencia de gobiernos democráticos, donde los representantes elegidos legítimamente, mediante el sufragio, cumplen con las leyes constitucionales, respetan los derechos y libertades individuales y de las minorías sin injerencia en los poderes legislativo y judicial.

De acuerdo al discurso que mantiene la Unión Europea, se puede interpretar que esta, considera a la democracia como un proceso, no como una imposición por parte de la comunidad en terceros países, en concordancia con los postulados de Seymour Lipset ${ }^{20}$ y menciona la necesidad de construir y mantener una cultura de derechos humanos y democracia con la incorporación de todos los sectores de la sociedad civil en trabajo conjunto con Parlamentos Democráticos Nacionales y otras instituciones gubernamentales.

Si bien es cierto, la asistencia para la democracia, de acuerdo a Carothers, como lo cita Carlos Santiso, "comprende la ayuda específicamente diseñada para promover la apertura de países no democráticos o favorecer la transición democrática en un país que ha experimentado la apertura democrática, tomando principalmente la forma de medidas positivas de apoyo e inducción", ${ }^{21}$ Elena Baracani $^{22}$ expone los factores internos y externos que han influido sustancial-

20 Seymour Martin Lipset, Repensando los requisitos sociales de la democracia, Revista La Política, España, 1996.

21 Carlos Santiso, Promoting Democracy by Conditioning AID? 2002. La traducción es mía. Tomado del Sitio Web: http://www.mafhoum.com/press3/100E18.pdf. Visitado el 14 de julio de 2009.

22 Elena Baracani, The European Union and democracy promotion: a strategy of democratization in the framework of the neighbourhood policy, Italia. La traducción es mía. Tomado del Sitio Web: http://www.fscpo.unict.it/EuroMed/baracani.pdf. Visitado el 14 de julio de 2009. 
mente para que la Unión Europea sea "la única, más diversa y avanzada institución internacional que promueve la democracia en los países en desarrollo".

Los factores internos citados por la autora son:

1. La Comunidad Económica Europea en 1957, su etapa inicial, dedicó un gran esfuerzo en la construcción de paz a través de la integración. La razón de Estado de la Unión Europea fue convertirse en un referente de los valores occidentales - democráticos para los países europeos y de todo el globo.

2. La Comunidad Europea empezó su vida con un énfasis en la cooperación económica como el principal medio para la construcción de la paz pero evolucionó hasta convertirse en una "Comunidad de Valores", que adoptó una forma similar al orden constitucional de los estados.

3. La Unión Europea perdió su potencial militar en la Segunda Guerra Mundial cuando sucumbió ante el régimen nazi y dependió de Estados Unidos para la victoria aliada, desde entonces una serie de tratados internacionales iniciaron la desmilitarización y el desarme de estos Estados. Precisamente la debilidad militar de la Unión Europea estimuló la formación de un poder civil que trata de promover la estabilidad en los países vecinos y en diferentes regiones mediante el desarrollo económico y comercial, la democracia, el buen gobierno y el Estado de derecho.

4. Durante el medio siglo anterior, la Comunidad evolucionó hacia una burocracia sofisticada con capacidad organizacional, importantes recursos materiales para influir en la política y con una creciente confianza sobre el rol de la futura Unión Europea en el escenario mundial. Lo que inicialmente apareció como un acuerdo de integración comercial, desembocó en una comunidad económica y posteriormente en una Unión basada en el régimen comunitario.

Los factores externos que se mencionaron en el texto de Baracani fueron los siguientes: 
1. En la mitad de la década de los setenta e inicios de los ochenta, la Comunidad facilitó la consolidación democrática en Grecia, España y Portugal que eran Estados con regímenes totalitarios que debían ser superados como una condición para su ingreso a la comunidad.

2. El colapso del bloque soviético a finales de los años ochenta e inicios de los años 90, confrontó a la Unión Europea con los peligros de una potencial inestabilidad y un hiper nacionalismo en los países que emergían de un sistema comunista lo cual podía poner en riesgo la estabilidad de la región. Por este motivo, en el año 2002, la Unión tomó la decisión de acoger a diez nuevos miembros.

3. La localización geográfica de los países de la Unión y la relativa estabilidad de sus miembros tanto en el ámbito político como económico permite mantener cierta apertura hacia otras regiones y generar estabilidad en los países aledaños y en otras regiones como el norte de África, el este de Mediterráneo, el Medio Oriente, Rusia, América Latina para la promoción de la democracia y la consecución de la paz.

4. Varios miembros de la Unión Europea tienen una historia colonial, especialmente en África, América Latina y Asia - Pacífico, lo cual involucra un mayor compromiso de la comunidad con la promoción de la democracia - especialmente desde la década de los sesenta - para romper con esa tradición de dominación y adoptar un sistema de cooperación a través de su ayuda y políticas de desarrollo para las excolonias.

Pero no solo Estados Unidos y la Unión Europea han adoptado a la democracia como bandera de lucha sino que, la Comunidad Internacional, a través de la Organización de las Naciones Unidas ha ejercido influencia en los países democráticos de occidente cuyos sistemas de gobierno estaban debilitados y aquellos que estaban dominados por regímenes comunistas totalitarios, para que cimienten la democracia. El fenómeno de la democratización ha marcado un impacto en la Organización de Naciones Unidas, puesto que Estados que recientemente han conseguido su independencia y han pasado a formar parte de la Organización -algunos formaban parte de la ex Unión Soviética- necesitan 
soporte para su consolidación como Estados soberanos y democráticos. Los mandatarios elegidos democráticamente han acudido a la Organización de Naciones Unidas para conseguir el apoyo económico y técnico para consolidar la democracia en las nuevas naciones independientes porque después de décadas de un sistema totalitario, los intereses en pugna son diversos.

\section{Promoción de la Democracia después de la Guerra Fría}

A inicios de la década de los 90 se creó el compromiso de los Estados occidentales para incluir en las agendas políticas la promoción de la democracia en los países en desarrollo, dando lugar al fortalecimiento de la democracia que se fundamenta en la idea de la "Paz democrática". Empero, la teoría de la "Paz Democrática" no considera que la garantía de mantener la paz mundial generaría como resultado a mediano plazo el recrudecimiento de las guerras entre Estados que no comparten ideología respecto al mejor régimen de gobierno y, también, hace una escasa mención sobre los conflictos intra estatales que precisamente tienen que ver con la forma de gobierno, aunque nominalmente este sea democrático.

Las políticas internacionales para promover la democracia no pueden superponerse a los factores internos de los países receptores, pues, en última instancia, son las características particulares las que determinan el éxito o no de los mecanismos externos que se han empleado. No existe un estandarización de medios a emplearse para promover la democracia a nivel mundial sino que depende más del interés del Estado.

De acuerdo con los principios de la ONU, la Democracia es el fundamento para que se garantice el respeto de los derechos y las libertades básicas de todo ser humano, ambas categorías se refuerzan mutuamente puesto que

la democracia está basada en la libre expresión del deseo de la gente para determinar sus propios sistemas políticos, económicos, sociales y culturales así como su total participación en cada aspecto de su vida. Dentro de este contexto, la promoción y protección de los derechos humanos y las libertades fundamentales a nivel nacional e internacional deberían ser universales y conducidas sin condiciones. La comunidad internacional debe apoyar el fortalecimiento y la 
promoción de la democracia, el desarrollo y el respeto de los derechos humanos y las libertades fundamentales en el mundo entero. ${ }^{23}$

\section{Tendencias en las relaciones de América Latina con la Unión Europea}

Entre 1808 y 1925 inician los procesos independentistas en América Latina, sobre todo de las naciones colonizadas por España. No obstante, los costos de las guerras y la debilidad política hizo que se pase de una dependencia colonial Europea a una dependencia económica norteamericana. La influencia de Estados Unidos se manifestó con la Doctrina Monroe que sirvió de argumento para muchas intervenciones (Colombia - Panamá) y posteriormente Cuba, Chile, Nicaragua a través del financiamiento de dictaduras de derecha.

Durante la Guerra Fría, Estados Unidos también buscó la incorporación de incentivos positivos para los países del tercer mundo como la creación de la United States Agency for International Development (USAID) y la iniciativa "Alianza para el Progreso" que buscaba la modernización del Estado pero desembocó en el masivo endeudamiento de las dictaduras que colapsaron la economía en la década de los 80 y 90. Al final de la Guerra Fría tanto Europa como Estados Unidos adoptaron el discurso de democratización a los países que habían sido parte de la Unión Soviética y a aquellos que tenían gobiernos dictatoriales.

No obstante, la figura del Estado se había desgastado durante un siglo y eso se evidencia en el ausentismo a los procesos electorales -Nicaragua y Colombia son los únicos países de América Latina que tienen procesos electorales voluntarios, sin embargo, en el primer país el 81,3\% del país asiste a sufragar mientras que en Colombia apenas se registra el 44,1 \%. -, la salida de divisas por el aumento del riesgo país, la desconfianza en las instituciones del Estado a causa de una evidente corrupción de funcionarios del Estado - Colombia ocupa el lugar 7 de 21 en América Latina, 70 en el mundo-.

23 Edward Newman, Roland Rich, The UN Role in promoting democracy. Beetween Ideals and Reality, UN Press, Estados Unidos, 2004. La traducción es mía. Tomado del Sitio Web: http://www.unu. edu/unupress/sample-chapters/UNrole.pdf. Visitado el 14 de julio de 2009. 


\section{Aplicación de la política europea de promoción de la demo- cracia y derechos humanos en Colombia}

El cercamiento de la cooperación europea a América Latina empezó en la década de los 50 con los acuerdos de primera generación que eran de índole comercial y se realizaban bilateralmente con los Estados más desarrollados de Sudamérica. A partir del año 2000 surge la idea de los Acuerdos de Cuarta Generación, o Acuerdos de Asociación que buscan fomentar la integración regional y tienen tres pilares: Diálogo Político, Cooperación, Comercio.

Las tres diferencias principales son: uso de recursos militares vs. Poder blando, top - down y bottom - up, proyectos de eliminación y proyectos de participación. La Unión Europea es vista únicamente como un ente de aportación económica.

De acuerdo a las condiciones que se analizaron anteriormente, puede pensarse que Colombia es una democracia sólida, pero es necesario debatir esta afirmación, pues si bien Colombia es la democracia más antigua de Sudamérica y no tiene un historial de golpes de estado, la apatía hacia la política se muestra en el ausentismo y la poca credibilidad que tienen las instituciones de gobierno a causa de un conflicto humanitario que ha durado 7 décadas.

Los desafíos de Colombia son:

1. La presencia de grupos irregulares que surgieron desde 1948 con el asesinato de Eliécer Gaitán y han ido adoptando un discurso de izquierda aunque se financian de la droga, la extorsión y los secuestros.

2. Las violaciones a los Derechos Humanos pues diariamente son asesinadas 19 personas en manos de las fuerzas armadas o de los grupos insurgentes.

3. Las drogas, Colombia se ha convertido en el principal productor de cocaína con un $57 \%$ de la producción mundial.

4. Migración y desplazamiento, el $10 \%$ de la población colombiana vive fuera del país como migrantes o refugiados y el número de desplazados 
internos ha aumentado en un $24 \%$ durante el 2008. Los principales actores del desplazamiento son las fuerzas armadas y la guerrilla.

Andrés Pastrana se encargó de internacionalizar el conflicto a través de su política de Diplomacia de Paz, proyectando la imagen de Colombia como una víctima del terrorismo y el narcotráfico. Desde esta perspectiva hizo un llamado a la comunidad internacional para que cooperen con Colombia en su lucha y condenen las acciones de las FARC y las AUC. Durante su periodo se creó un territorio de distensión que por la falta de negociación se convirtió en un terreno donde los grupos irregulares podían moverse sin intervención del Estado. Además, las negociaciones se paralizaron con la implementación del Plan Colombia.

Cuatro años después, Álvaro Uribe asumió la presidencia en el año 2002, con una política de Tolerancia Cero hacia los grupos insurgentes, llamando a la comunidad internacional a que los incluyan en la lista de terroristas mundiales y aprovechando estratégicamente los hechos del 11 de septiembre. En el 2003 se creó la Política de Defensa y Seguridad Democrática como una forma de terminar con la violencia interna -sin importar los métodos-también se creó la Ley de Justicia y Paz para desmovilizar a las AUC, garantizando la amnistía a los exmilitantes del grupo a cambio de que declaren los crímenes cometidos y también canjes humanitarios.

El límite entre la política interna y externa de Colombia se ha perdido en estos dos períodos.

\section{Impactos de la iniciativa europea de promoción de la De- mocracia y Derechos Humanos en Colombia}

Durante los últimos 15 años se han realizado tres cumbres de Estado entre los países de América Latina y El Caribe con la Unión Europea para afianzar las relaciones biregionales. Las agendas pusieron particular énfasis en la región andina y sobre todo en Colombia. En 2004, el interés preferencial en Colombia se expresa en la evaluación realizada por el jefe de la delegación europea: "En la región, Colombia es importante porque cuenta con una posición geográfica estratégica en el hemisferio americano. Por una parte, es un punto de enlace entre los países del norte y del sur en el hemisferio; y, por otra, posee amplias costas sobre los océanos Atlántico y Pacífico. Dicha ubicación le permite ser 
la puerta de entrada a América del Sur y disponer de puertos hacia el resto de América, Europa y los países de la Cuenca del Pacífico. Colombia juega un rol de liderazgo importante para promover las relaciones comerciales entre la UE y la CAN. Las relaciones comerciales entre los dos bloques han aumentado considerablemente en las últimas dos décadas, pasando de 9 billones de euros en 1980 a 15.5 billones de euros en el 2002". ${ }^{24}$

En la última década, la UE se ha convertido en el primer inversor en la región andina como conjunto, ya que representa más de una cuarta parte del total de inversión extranjera directa y es el principal donante de ayuda internacional para el desarrollo: "La cooperación programable para el período 2002-2006 otorgada por la Comisión Europea asciende a 475 millones de euros para la región y la ayuda no reembolsable de la UE, es decir, considerando los aportes que realiza la Comisión Europea y los Países Miembros en sus relaciones bilaterales, supera los 1,000 millones de euros para la CAN y 422 millones para Colombia". ${ }^{25}$

Las prioridades europeas se han manifestado sobre todo en el apoyo al proceso andino de integración y a la construcción de la Zona Andina de Paz, entendiendo que no se conseguirá en tanto persista el conflicto armado en Colombia, y que también representa una amenaza a la seguridad europea. Por otro lado, los problemas internos de la Comunidad Andina de Naciones se han agudizado debido a las negociaciones que Estados Unidos desarrolla bilateralmente para firmar tratados de libre comercio con Ecuador, Colombia y Perú (excluyendo a Venezuela y Bolivia). La política europea más bien ha buscado consolidar la integración andina. No por ello ha evitado cometer los mismos errores que critica a Estados Unidos pues los países miembros defienden más sus intereses comerciales particulares que los de la Unión Europea como conjunto.

La construcción de la Unión Europea como actor internacional también es puesta a prueba dentro de su participación en el conflicto colombiano, congruente con su política exterior basada en el compromiso declarado con la paz,

24 Adrianus Koetsenruijter, Embajador, Jefe de la Delegación de la Comisión Europea para Colombia y Ecuador, FESCOL, 14 de Octubre de 2004. Tomado del Sitio Web: http://www.delcol.ec.europa. eu/es/novedades/boletin_182.htm. Visitado el 14 de enero de 2010

25 Centro de Investigación para la Paz, La Unión Europea y Colombia en una Encrucijada, Madrid, 2006. Tomado del Sitio Web: http://www.cipresearch.fuhem.es/pazyseguridad/docs/documento estrategico_2_UEColombia.pdf. Visitado el 20 de agosto de 2009. 
la democracia y el desarrollo. Sin dudas, este conflicto es un atentado contra los cuatro principios básicos ${ }^{26}$ que defiende la Unión Europea como comunes a todos los Estados miembros; sin embargo, no existe una política de acción europea homogénea, estable y duradera, dado que las prioridades que cada uno de los estados miembros establece difieren entre sí tanto a nivel ideológico ${ }^{27} \mathrm{y}$ también a nivel comercial. ${ }^{28}$ Un ejemplo de estas discrepancias surgió en el año 2001 cuando los quince miembros de la Unión Europea de entonces se negaron a incluir a las Fuerzas Activas Revolucionarias de Colombia (FARC) y a las Autodefensas Unidas de Colombia (AUC) dentro de la lista de organizaciones terroristas del mundo. Esta acción diplomática fue criticada por el Gobierno de Pastrana pues consideraba a la Unión como su aliado dentro de la lucha contra las fuerzas irregulares. Posteriormente en el año 2002, e influenciados por la creciente preocupación mundial sobre la seguridad luego de los atentados del 11 de septiembre, la UE optó por actualizar la lista de personas y organizaciones consideradas como terroristas en las cuales se incluye a los grupos insurgentes de Colombia, las FARC, el ELN.

Sin embargo, hay dificultades tanto a nivel regional como interregional que deben ser subsanadas para garantizar la consecución de los resultados esperados con la cooperación entre la Unión Europea y la Comunidad Andina:

- En el área andina, hay conflictos ideológicos entre los gobiernos socialistas del siglo XXI que son Ecuador y Bolivia frente a los liberales que son Colombia y Perú. Las diferencias ideológicas impidieron que se firmara el acuerdo de asociación regional como estaba previsto en el año 2008. Además, las relaciones entre Colombia y Ecuador están suspendidas desde ese año por el ataque en Angostura.

26 Estos principios se encuentran mencionados en el artículo 6 del Tratado Constitutivo de la Unión Europea y son: Libertad, Democracia, Respeto a los Derechos Humanos y Libertades Fundamentales y, el Estado de Derecho.

27 Por ejemplo hay países que están más alineados a la ideología de Estados Unidos y que por ello son más radicales en cuanto al combate antidrogas, la migración y el terrorismo. Los países que mantienen esta línea son Gran Bretaña e Italia.

28 Existen países como España que dan preferencias arancelarias a los productos de las Islas Canarias por ser parte de su jurisdicción, yéndose incluso en contra de los principios de la Organización Mundial de Comercio. 
- La política del retorno y el litigio por la imposición de aranceles al banano latinoamericano han generado serios roces entre los gobiernos latinoamericanos y europeos, por lo cual, no se ha dado un exhaustivo seguimiento a las negociaciones.

- A nivel interno, Europa tiene problemas en ponderar los ideales comunes sobre los intereses comerciales particulares de cada Estado, situación que se agravó con la ampliación a 27 miembros en el año 2007.

- El modelo de promoción de la democracia adoptado por la IEDDH no se adapta a todas las realidades de los países porque los países del este de Europa y de Latinoamérica son diferentes tanto en cultura como en idioma y religión y no se puede aplicar el mismo modelo para todos.

- La presencia de Estados Unidos ha limitado la participación europea en el conflicto colombiano ya que Uribe tiene una visión militarista para resolver la violencia interna mientras que Europa tiene una visión completamente diferente y por ello en ocasiones ha sido solamente el financista de estos proyectos o se ha limitado a realizar modestos proyectos. Europa considera que debe poner fin a la violencia pero dentro del marco del Estado de Derecho.

\section{Conclusiones}

Al finalizar la disertación, podemos contar con algunas respuestas que formulamos a continuación:

1. Cualquier inversión realizada por la Unión Europea, Estados Unidos y otros organismos internacionales como la Organización de Naciones Unidas y sus filiales siempre resultarán insuficientes para conseguir una paz duradera en el territorio colombiano y defender los principios del Estado de Derecho, la Democracia y los Derechos Humanos. No solo porque los esfuerzos están dispersos y corresponden a ideologías diferentes -por un lado está el criterio militarista de Estados Unidos y por otro lado el fortalecimiento de la sociedad civil que promueve la Unión Europea- sino porque las soluciones pensadas desde el exterior de la 
sociedad nacional no son suficientes si no se articulan con las aquellas que deben provenir de la solución de los problemas internos a partir de la voluntad de los actores nacionales en emprender cambios estructurales profundos largamente arrastrados, que son en último término provienen las raíces históricas de la situación.

2. Las relaciones internacionales han cambiado desde el atentado del 11 de septiembre de 2001. Los Estados Unidos impusieron como amenaza fundamental para todos los Estados desarrollados, la lucha contra el terrorismo internacional y emprendieron una "guerra" contra una amenaza difícil de solucionar por esta vía. Aunque en un comienzo algunos países de la Unión Europea terminaron por adherirse al plan norteamericano, poco después han diversificado sus opciones, de modo que la Iniciativa Democrática patrocinada por la UE en América Latina y sobre todo en Colombia (que quedó inmersa en la estrategia antiterrorista) orientó sus esfuerzos económicos, técnicos y diplomáticos para apoyar los procesos de paz y disminuir los impactos humanos del conflicto, agravado por el narcotráfico que fortalece la existencia de grupos irregulares como el Ejército de Liberación Nacional, las Fuerzas Armadas Revolucionarias de Colombia y las Autodefensas Unidad de Colombia.

El interés europeo en intervenir en el área andina no se debe únicamente a los vínculos históricos que mantiene con la subregión, sino a su interés -como Unión Europea- de convertirse en actor político relevante a nivel internacional, amparado en el prestigio adquirido por su sistema de integración basado en los principios compartidos ${ }^{29} \mathrm{y}$ disminuir la injerencia norteamericana en este territorio. Al área andina le conviene el acercamiento europeo ya que puede obtener de éste beneficios -aparentemente más amplios- aunque al momento los resultados sean todavía exiguos en comparación con la magnitud del conflicto.

3. Efectivamente, una de las constantes encontradas en esta disertación es que Europa mantiene el anhelo de recuperar su protagonismo a escala 
mundial, pero su objetivo no se despliega en términos de poder en el sentido que se plantea en la teoría realista. Más bien, es posible que se enfoque principalmente en una política de prestigio que le permita exportar su riqueza valórica en torno a la paz y la convivencia democrática para alcanzar una posición relevante dentro de un sistema multipolar que se abre. El multilateralismo que fomenta aparece como el principal instrumento para la resolución de conflictos, a la vez que se vuelve un referente en términos de cooperación internacional que tienen el reconocimiento de ser la única entidad internacional que ha logrado la convergencia de países que décadas anteriores habían estado enfrentados en un conflicto mundial. Esta experiencia ha sido volcada hacia la elección de Colombia como un país prioritario ya que éste es el "prototipo de problema que puede resolverse por una vía alternativa al uso de la fuerza.

La democracia que se promueve desde la Unión Europea se basa en el principio de bottom - up, es decir, busca fortalecer los principios democráticos en la sociedad civil mediante el apoyo de programas de desarrollo local y participación ciudadana para que tengan un criterio político más desarrollado y exijan el cumplimiento de sus derechos en un sistema democrático. Al contrario, podemos decir que los Estados Unidos han promovido una democracia top down, basada en su interés por mantener las estructuras de su política internacional; en sus propios instrumentos y metas para generar el modelo de democracia que promueve, básicamente electoral e institucionalista, basada en la forma más que en el contenido; y en una paz conseguida mediante el mecanismo de la intervención militar como se ha visto en América Latina ${ }^{30}$, Europa $^{31}$ y Medio Oriente ${ }^{32}$.

4. El conflicto colombiano ha sido el más grave de la historia contemporánea en América Latina y ha producido una de las peores crisis humanitarias,

30 Desde 1823, con la Doctrina Monroe, América Latina ha estado bajo la intervención política, económica y militar de los Estados Unidos.

31 Los postulados del Tratado de Versalles, se basaron en la intervención de las potencias aliadas en los territorios ocupados por las potencias del eje.

32 En Medio Oriente los países en los que ha intervenido Estados Unidos militarmente han sido Afganistán e Irak y se han instaurado sistemas democráticos porque tienen elecciones aunque se han despertado serias dudas sobre la veracidad de los resultados. 
dado el elevado número de víctimas entre muertos y desplazados internos; y puede ser percibido como una amenaza para los intereses nacionales de los Estados europeos y para los intereses de la Comunidad europea en general. Estos elementos pueden relacionarse con la protección de los intereses geopolíticos que promueve en sus relaciones con América Latina, donde el conflicto colombiano realmente presenta una amenaza a la seguridad regional, y por ende a la seguridad mundial por la multiplicidad de vínculos establecidos mundialmente por este conflicto y especialmente con la Unión Europea cuyos países se ven afectados por las formas de comercio ilícito de la droga, por los tentáculos ocultos de las mafias internacionales que operan a través del sistema financiero internacional y por muchos otros factores, entre ellos la emigración y el refugio.

Desde la década de los años 50, apoyados por el Plan Marshal, los países de Europa Occidental empezaron a juntar esfuerzos para superar la devastación ocasionada por dos conflictos mundiales. A fines de los años ochenta, una vez que Europa se vio fortalecida política y económicamente, volteó su mirada hacia otras regiones del mundo con el interés de convertirse en un referente político internacional a partir de sus propios valores democráticos. Participó activamente en los procesos que precedieron a la Declaración de Esquipulas I y II para sentar un nuevo referente de pacificación a través del diálogo y el multilateralismo en lugar del tradicional intervencionismo militar. Dentro del Acuerdo Constitutivo de la Unión Europea, los Derechos Humanos y la democratización constituyen un vasto tema que abarca diversos ámbitos de actividad, como la política exterior y de seguridad común (PESC), la cooperación financiera, el comercio y la inmigración.

5. Los países donantes parten de una idea de la Democracia que puede ser considerada como un "Tipo Ideal" ${ }_{33}$ y desean que la realidad de los países asistidos se amolde a esta abstracción en lugar de flexibilizar los modelos de promoción de la democracia en consideración con las particularidades que viven los Estados. Quizás ésta sea la variable más conflictiva

33 (Guiddens 1971) Para Weber "Un tipo ideal es una construcción basada en la abstracción y la combinación de un número indefinido de elementos que, aunque se encuentran en la realidad, rara vez o nunca se descubren de esta forma específica." 
entre los países donantes y los países receptores de la ayuda puesto que los tipos ideales no se encuentran en la realidad y difieren de acuerdo a los elementos que se incluyan en ellos. En la Unión Europea existe un esfuerzo claro para "exportar" sus valores democráticos y distinguirlos de los principios norteamericanos. Pero el modelo europeo de democracia y bienestar, basado en el multilateralismo y la integración como principios deseables son, a decir de algunos analistas, poco sensible respecto "de las culturas y valores nacionales o locales; no permite la exploración de sistemas funcionales equivalentes a los principios democráticos europeos en sistemas débiles o fallidos". ${ }^{34}$

El apoyo europeo en América Latina y en todo el mundo se basa en el fortalecimiento de la sociedad civil y no incluye la intervención militar sino que se limita a transmitir incentivos positivos hacia los Estados para enfatizar la diplomacia multilateral que es el emblema de la Comunidad. Los mecanismos empleados son básicamente los mismos en las regiones de Asia, Europa del Este, África y América Latina. Las diferencias se basan en la asignación de presupuestos y el énfasis que se le pone una $\mathrm{u}$ otra región o Estado. "La Unión Europea sigue un solo patrón cultural que es usado para promover la Democracia, los Derechos Humanos y el Estado de Derecho alrededor del mundo. Con la Iniciativa Europea de Promoción de la Democracia y Derechos Humanos se ha establecido un diseño estandarizado de procedimientos que supone ser el "mantra" de la promoción democrática de Europa" (Ibíd).

6. La complejidad institucional de la Unión Europea se debe a la ampliación del organismo a 27 miembros, por lo cual es más difícil mantener y promulgar los valores compartidos por todos los Estados que la conforman pues se corre el riesgo de que cada uno defienda sus intereses particulares sobre los beneficios de la comunidad. Las divergencias de opinión, que ya se vieron en relación con la guerra de Irak, existen también con relación a Colombia, pues algunos Estados tienen más afinidad con la intervención norteamericana, la criminalización de la migración y 
una lucha centrada en el ataque a la producción de la droga en lugar de disminuir la demanda.

La evidencia recopilada durante la investigación arroja varias limitaciones que impiden el desarrollo de unas fluidas relaciones entre Europa y América Latina, especialmente, la región andina:

- En primer lugar, se entiende por dificultades administrativas a la falta de delegados europeos que hablen español con fluidez y conozcan a profundidad la situación social, en este caso, de los departamentos colombianos en los que ejecutarán proyectos. Las gestiones para asuntos considerados relevantes, deben esperar una respuesta desde Bruselas para iniciar su acción lo cual retarda las soluciones y los ciudadanos que desean conocer más sobre la Unión pueden hacerlo únicamente mediante correos electrónicos y no por visitas personales.

- En segundo lugar, las dificultades estructurares corresponden a aquellas que tiene la Unión como fruto de su proceso de ampliación hacia 27 miembros, lo cual ha retraído la cooperación internacional a la vez que se complican la toma de decisiones porque los miembros no logran llegar a acuerdos con facilidad.

- Por último, las políticas implementadas por el Gobierno de Uribe dentro de la "Seguridad Democrática" que restringe la cooperación internacional a determinados parámetros que van contra el espíritu de los principios europeos pues, si bien es cierto, el país receptor de la ayuda debe sugerir el destino de los fondos entregados por la cooperación internacional, no puede exigir que se use para actividades que no forman parte de la política europea como el Plan Colombia propuesto por Estados Unidos. 